\title{
Interactions of vanadium(V)-citrate complexes with the sarcoplasmic reticulum calcium pump
}

\author{
Manuel Aureliano ${ }^{\text {a,* }}$, Teresa Tiago ${ }^{\text {a }}$, Ricardo M.C. Gândara ${ }^{a}$, Andrea Sousa ${ }^{a}$, \\ A. Moderno ${ }^{\text {a }}$, M. Kaliva ${ }^{\text {b }}$, A. Salifoglou ${ }^{\text {c,d }}$, Rui O. Duarte ${ }^{\text {e, José J.G. Moura }}{ }^{\text {e }}$ \\ ${ }^{a}$ CBME, Department of Chemistry and Biochemistry, FCT, University of the Algarve, 8005-139 Faro, Portugal \\ ${ }^{\mathrm{b}}$ Department of Chemistry, University of Crete, Heraklion 71409, Greece \\ ${ }^{\mathrm{c}}$ Department of Chemical Engineering, Aristotle University of Thessaloniki, Thessaloniki 54124, Greece \\ ${ }^{d}$ Chemical Process Engineering Research Institute, Thermi, Thessaloniki 57001, Greece \\ e REQUIMTE-CQFB, FCT, Universidade Nova de Lisboa, 2829-516 Caparica, Portugal
}

Received 5 July 2005; received in revised form 5 September 2005; accepted 7 September 2005

Available online 10 October 2005

\begin{abstract}
Among the biotargets interacting with vanadium is the calcium pump from the sarcoplasmic reticulum (SR). To this end, initial research efforts were launched with two vanadium $(\mathrm{V})$-citrate complexes, namely $\left(\mathrm{NH}_{4}\right)_{6}\left[\mathrm{~V}_{2} \mathrm{O}_{4}\left(\mathrm{C}_{6} \mathrm{H}_{4} \mathrm{O}_{7}\right)_{2}\right] \cdot 6 \mathrm{H}_{2} \mathrm{O}$ and $\left(\mathrm{NH}_{4}\right)_{6}\left[\mathrm{~V}_{2} \mathrm{O}_{2}\left(\mathrm{O}_{2}\right)_{2}\left(\mathrm{C}_{6} \mathrm{H}_{4} \mathrm{O}_{7}\right)_{2}\right] \cdot 4 \mathrm{H}_{2} \mathrm{O}$, potentially capable of interacting with the SR calcium pump by combining kinetic studies with ${ }^{51} \mathrm{~V}$ NMR spectroscopy. Upon dissolution in the reaction medium (concentration range: 4-0.5 mM), both vanadium(V):citrate (VC) and peroxovanadium(V):citrate (PVC) complexes are partially converted into vanadate oligomers. A $1 \mathrm{mM}$ solution of the PVC complex, containing $184 \mu \mathrm{M}$ of the PVC complex, $94 \mu \mathrm{M}$ oxoperoxovanadium(V) (PV) species, $222 \mu \mathrm{M}$ monomeric (V1), $43 \mu \mathrm{M}$ dimeric (V2) and $53 \mu \mathrm{M}$ tetrameric (V4) species, inhibits $\mathrm{Ca}^{2+}$ accumulation by $75 \%$, whereas a solution of the VC complex of the same vanadium concentration, containing $98 \mu \mathrm{M}$ of the VC complex, $263 \mu \mathrm{M}$ monomeric (V1), $64 \mu \mathrm{M}$ dimeric (V2) and $92 \mu \mathrm{M}$ tetrameric (V4) species inhibits the calcium pump activity by $33 \%$. In contrast, a $1 \mathrm{mM}$ metavanadate solution, containing $460 \mu \mathrm{M}$ monomeric (V1), $90.2 \mu \mathrm{M}$ dimeric (V2) and $80 \mu \mathrm{M}$ tetrameric (V4) species, has no effect on $\mathrm{Ca}^{2+}$ accumulation. The NMR signals from the VC complex $(-548.0 \mathrm{ppm})$, PVC complex $(-551.5 \mathrm{ppm})$ and PV $(-611.1 \mathrm{ppm})$ are broadened upon SR vesicle addition $(2.5 \mathrm{mg} / \mathrm{ml}$ total protein). The relative order for the half width line broadening of the NMR signals, which reflect the interaction with the protein, was found to be $\mathrm{V} 4>\mathrm{PVC}>\mathrm{VC}>\mathrm{PV}>\mathrm{V} 2=\mathrm{V} 1=1$, with no effect observed for the V1 and V2 signals. Putting it all together the effects of two vana$\operatorname{dium}(\mathrm{V})$-citrate complexes on the modulation of calcium accumulation and ATP hydrolysis by the SR calcium pump reflected the observed variable reactivity into the nature of key species forming upon dissolution of the title complexes in the reaction media.
\end{abstract}

(C) 2005 Elsevier Inc. All rights reserved.

Keywords: Vanadium-citrate complex; Calcium pump

\section{Introduction}

Almost 30 years after the discovery that vanadium was a muscle inhibiting factor and a $\mathrm{Na}^{+} / \mathrm{K}^{+}$-ATPase inhibitor present in commercially available ATP [1-3], it still remains to be clarified whether or not vanadium has a physiological

\footnotetext{
* Corresponding author. Tel.: +351965 536 476; fax: +351 289819403. E-mail address: maalves@ualg.pt (M. Aureliano).
}

role in the muscle. It is believed that the complex chemistry of vanadium itself, its interactions with small molecules of biological interest, and vanadate similarities with phosphate constitute the rudiments of research emerging from the increased interest in vanadium in biological systems. Among the effects attributed to vanadium salts and complexes, the insulin mimetic action stands prominent $[4,5]$. However, vanadium toxicity and poor absorption in the gastrointestinal tract is still a major obstacle in the development of therapeutic applications [6]. The challenge of 
overcoming these obstacles has spurred considerable research activity, targeting the interaction of vanadium with biomolecules and organic ligands, in order to enhance absorption and efficiency while concurrently reducing toxicity. To that end, a number of ligands, such as citric acid, have been employed as potential ligand binders of vanadium in biological systems [7-9].

It is known that vanadium ions and vanadium complexes inhibit or stimulate the activity of various enzymes. In the case of the membrane bound $\mathrm{E} 1-\mathrm{E} 2 \mathrm{Ca}^{2+}$-ATPase (calcium pump) from sarcoplasmic reticulum (SR), the inhibition is promoted by orthovanadate binding to the E2 conformation of the protein [10]. Moreover, the use of vanadate is related to the catalytic site of $\mathrm{Ca}^{2+}$ ATPase, which contains an aspartyl that is phosphorylated during the catalytic cycle thereby forming an acyl phosphate anhydride [11]. In addition to monomeric vanadate species, it has been reported that other vanadate oligomers interact with the SR calcium pump [12]. It has been demonstrated that some of the interactions, e.g. decameric species, disrupt the energy coupling and enzyme turnover. Other interactions of vanadium, e.g. monomeric species, may have no implicit effect or even improve the coupling to the $\mathrm{Ca}^{2+}$ pump [13]. The SR calcium pump was reported to have a decreased activity in some diabetic conditions, which could result in impaired cardiac relaxation [14]. Several studies have been carried out using vanadium(V) for characterization of SR calcium pump $[13,15]$. Indeed, SR calcium pump has proven to be an excellent model to study $\mathrm{Ca}^{2+}$ homeostasis affected by acute and cronic exposure of nitrosative stress [16].

In the present study, the effects of two vanadium( $\mathrm{V}$ )citrate complexes namely $\left(\mathrm{NH}_{4}\right)_{6}\left[\mathrm{~V}_{2} \mathrm{O}_{4}\left(\mathrm{C}_{6} \mathrm{H}_{4} \mathrm{O}_{7}\right)_{2}\right] \cdot 6 \mathrm{H}_{2} \mathrm{O}$ and $\left(\mathrm{NH}_{4}\right)_{6}\left[\mathrm{~V}_{2} \mathrm{O}_{2}\left(\mathrm{O}_{2}\right)_{2}\left(\mathrm{C}_{6} \mathrm{H}_{4} \mathrm{O}_{7}\right)_{2}\right] \cdot 4 \mathrm{H}_{2} \mathrm{O}$, on the modulation of calcium accumulation and ATP hydrolysis by the SR calcium pump were evaluated. The results demonstrated that it is of primary importance to precisely characterize the aqueous behaviour of the vanadium $(\mathrm{V})$ species and their interactions with the investigated biosystem prior to attempting to understand the promoted effects. Both vanadium(V)-citrate complexes interact and affect the activity of the SR calcium pump, with the peroxovana$\operatorname{dium}(\mathrm{V})$ :citrate complex solutions being the most potent inhibitor.

\section{Materials and methods}

\subsection{Reagents}

Chemicals used to prepare buffers were of reagent grade. Ammonium metavanadate and citric acid were purchased from Riedel-de Haën. ATP (vanadium free) was supplied by Sigma. All other reagents were of biochemical analysis grade from $\mathrm{BDH}$, Merck or Sigma.

The synthesis of the vanadium $(\mathrm{V})$ complexes $\left(\mathrm{NH}_{4}\right)_{6}\left[\mathrm{~V}_{2} \mathrm{O}_{4}\left(\mathrm{C}_{6} \mathrm{H}_{4} \mathrm{O}_{7}\right)_{2}\right] \cdot 6 \mathrm{H}_{2} \mathrm{O}$ and $\left(\mathrm{NH}_{4}\right)_{6}\left[\mathrm{~V}_{2} \mathrm{O}_{2}\left(\mathrm{O}_{2}\right)_{2}\right.$ $\left.\left(\mathrm{C}_{6} \mathrm{H}_{4} \mathrm{O}_{7}\right)_{2}\right] \cdot 4 \mathrm{H}_{2} \mathrm{O}$ was achieved according to published lit- erature procedures $[17,18]$. In these articles, the characterization of the complexes was carried out with analytical, spectroscopic techniques (UV-Visible, ${ }^{13} \mathrm{C}$ NMR (in the case of the ternary vanadium(V)-peroxo-citrate complex), FT-IR) and X-ray crystallographic techniques. Therefore, the structures of the two complexes are known along with their chemical reactivity. The ${ }^{51} \mathrm{~V}$ NMR, however, is not available for the two species and thus cannot be included in this manuscript.

Vanadium-citrate complex stock solutions $(9 \mathrm{mM})$ used in the studies were prepared from vanadium $(\mathrm{V})$-citrate $\left(\mathrm{NH}_{4}\right)_{6}\left[\mathrm{~V}_{2} \mathrm{O}_{4}\left(\mathrm{C}_{6} \mathrm{H}_{4} \mathrm{O}_{7}\right)_{2}\right] \cdot 6 \mathrm{H}_{2} \mathrm{O}$ and from vanadium(V)peroxo-citrate $\left(\mathrm{NH}_{4}\right)_{6}\left[\mathrm{~V}_{2} \mathrm{O}_{2}\left(\mathrm{O}_{2}\right)_{2}\left(\mathrm{C}_{6} \mathrm{H}_{4} \mathrm{O}_{7}\right)_{2}\right] \cdot 4 \mathrm{H}_{2} \mathrm{O}$ salts in a medium containing $25 \mathrm{mM}$ Hepes (2-(4-(2-hydroxyethyl)-1-piperazinyl)ethanesulphonic acid), $\mathrm{pH}$ 7.0, and $0.1 \mathrm{M} \mathrm{KCl}$.

\subsection{Preparation of sarcoplasmic reticulum vesicles}

Sarcoplasmic reticulum vesicles (SRV) were prepared from white skeletal rabbit muscles as described elsewhere [13]. Isolated SRV suspended in $\mathrm{KCl} 0.1 \mathrm{M}$, tris(hydroxymethyl)aminometane (Tris) $10 \mathrm{mM}$ (pH 7.0) were diluted $1: 1$ with sucrose $2 \mathrm{M}$ and frozen in liquid nitrogen prior to storage at $-80^{\circ} \mathrm{C}$. For SRV preparations used in NMR studies, no sucrose was added, once sucrose forms complexes with vanadium and in the ${ }^{51} \mathrm{~V}$ NMR appears two signals at -540 and $-550 \mathrm{ppm}$ as described previously [13]. Protein concentration was determined by the biuret method, using bovine serum albumin as a standard [19]. The percentage of each protein present in the SRV preparations was determined trough densitometry analysis of sodium dodecyl sulphate (SDS)-polyacrylamide gel electrophoresis $\left(7.5 \%\right.$ acrylamide). The SR $\mathrm{Ca}^{2+}$-ATPase analysed by SDS-polyacrylamide gel electrophoresis was at least $70 \%$ of the total protein in SRV.

\subsection{NMR measurements}

${ }^{51} \mathrm{~V}$ Nuclear magnetic resonance spectroscopy measurements on vanadium(V)-citrate complex solutions were taken on a Bruker AM- $400 \mathrm{MHz}$, by using a $90^{\circ}$ pulse Fourier transform technique. Chemical shift values are given with reference to $\mathrm{VOCl}_{3}(0 \mathrm{ppm})$ as a standard. The relative areas of several free and bound vanadate resonances were integrated and the line widths were obtained by subtracting the value $(20 \mathrm{~Hz})$ used in line broadening. The concentrations of vanadate oligomers $\mathrm{V}_{x}$ were calculated from the fractions of the total integrated areas observed in the recorded spectra as described in the equation below. The symbol $A$ corresponds to the area measured for the $x$ vana$\operatorname{dium}(\mathrm{V})$ species $\left(\mathrm{V}_{x}\right)$ with $n$ being the aggregation number (number of vanadium atoms), $A\left(\mathrm{~V}_{t}\right)$, the sum of the measured area and $\left[\mathrm{V}_{t}\right]$ the total vanadium $(\mathrm{V})$ concentration

$\left[\mathrm{V}_{x}\right]=A\left(\mathrm{~V}_{x}\right) \cdot \frac{1}{A\left(\mathrm{~V}_{t}\right)} \cdot \frac{\left[\mathrm{V}_{t}\right]}{n\left(\mathrm{~V}_{x}\right)}$. 
The spectra of vanadium(V)-citrate complex solutions (VC and PVC complexes) were obtained at several concentrations in the reaction medium, containing $\mathrm{KCl} 0.1 \mathrm{M}$, $\mathrm{MgCl}_{2} 5 \mathrm{mM}$, Hepes $25 \mathrm{mM}$ (pH 7.0), $\mathrm{CaCl}_{2} 50 \mu \mathrm{M}$ and ATP $500 \mu \mathrm{M}$ in Hepes $25 \mathrm{mM}$ (pH 7.0). Spectra of $2 \mathrm{mM}$ vanadium $(\mathrm{V})$-citrate complex solutions were also obtained in the same reaction medium, in the absence and presence of $2.5 \mathrm{mg} / \mathrm{ml}$ of SR preparations. The spectra were acquired at room temperature, spectral with $40,355 \mathrm{~Hz}$, accumulation time $0.05 \mathrm{~s}$, number of transients between 12,000 and 25,000 and relaxation delay $0.01 \mathrm{~s}$. For quantitative measurements all of the spectral parameters were kept constant [12].

\subsection{ATP hydrolysis by calcium pump}

ATP hydrolysis was measured by colorimetric determination of inorganic phosphate [20]. Kinetic experiments were performed at $25^{\circ} \mathrm{C}$ in a reaction medium containing $\mathrm{KCl} 0.1 \mathrm{M}$, Hepes $25 \mathrm{mM}$ (pH 7.0), $\mathrm{MgCl}_{2} 5 \mathrm{mM}, \mathrm{CaCl}_{2}$ $50 \mu \mathrm{M}, 0.285 \mathrm{~g} / \mathrm{ml}$ of SRV preparations, in the absence or presence of $1 \mathrm{mM}$ vanadate, vanadium(V) complexes or citrate, according to the required experimental conditions. Vanadate, vanadium-citrate complexes or citrate solutions were added to the medium prior to protein addition. The reaction was initiated by adding Mg-ATP $500 \mu \mathrm{M}$ and was subsequently monitored for up to $20 \mathrm{~min}$.

\section{5. $\mathrm{Ca}^{2+}$ uptake experiments}

$\mathrm{Ca}^{2+}$ uptake experiments were performed as described elsewhere [12]. The experiments were carried out at $25^{\circ} \mathrm{C}$ in a $4 \mathrm{ml}$ assay medium, containing $\mathrm{KCl} 0.1 \mathrm{M}, \mathrm{MgCl}_{2}$ $5 \mathrm{mM}$, Hepes $25 \mathrm{mM}$ (pH 7.0), $\mathrm{CaCl}_{2} 20 \mu \mathrm{M}$, and $0.1 \mathrm{mg} / \mathrm{ml} \mathrm{SR}$ preparations. The reaction was initiated by adding ATP $500 \mu \mathrm{M}$ in Hepes $25 \mathrm{mM}$ (pH 7.0). At the end of each experiment, an internal calibration was performed by addition of standard $\mathrm{CaCl}_{2}$ solutions. Vana$\operatorname{dium}(\mathrm{V})$-citrate complex or metavanadate solutions at several concentrations were added to the medium prior to ATP addition.

\section{Results and discussion}

\subsection{Spectroscopic characterization of the complexes}

The ${ }^{51} \mathrm{~V}$ NMR spectra of $9 \mathrm{mM}$ solutions of the vana$\operatorname{dium}(\mathrm{V})$ :citrate complex (VC) in water ( $\mathrm{pH}$ 6.6) exhibit resonances at -546 and at $-549 \mathrm{ppm}$ (Fig. 1). The relative areas of the resonances reflect a 1:1 ratio, with the half line width of these signals being very similar $(180 \pm 10 \mathrm{~Hz})$. When the VC complex solution was prepared in the reaction medium, another NMR signal was detected at $-578 \mathrm{ppm}$. Upon dissolution, of the VC complex, in the reaction medium at lower concentrations (from 4 to $0.5 \mathrm{mM}$ ), the $\mathrm{VC}$ complex is partially converted into vanadate oligomers (Fig. 2). NMR signals ascribed to mono

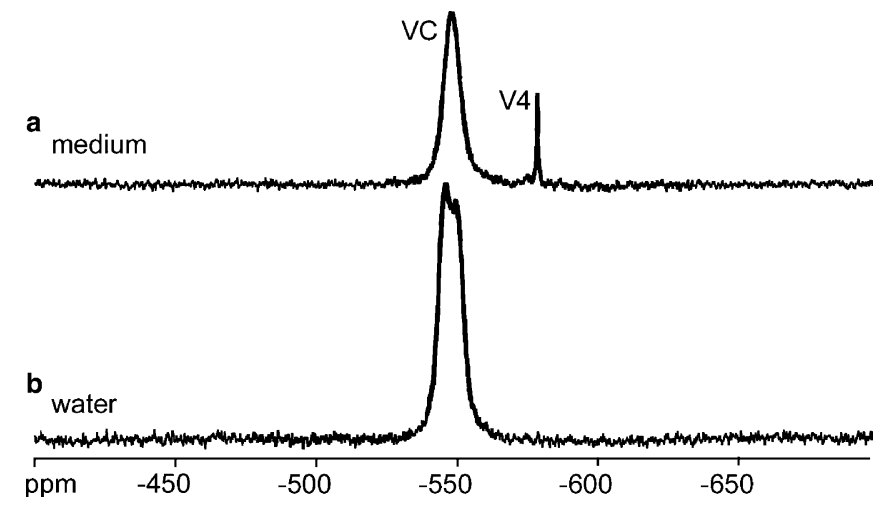

Fig. 1. $105.2 \mathrm{MHz}{ }^{51} \mathrm{~V}$ NMR spectra, at $22{ }^{\circ} \mathrm{C}$, of a $9 \mathrm{mM}$ vanadium(V)citrate complex solution prepared in water (a) or in the reaction medium (b). VC and V4 stands for vanadium(V)-citrate and tetrameric vanadate species, respectively.

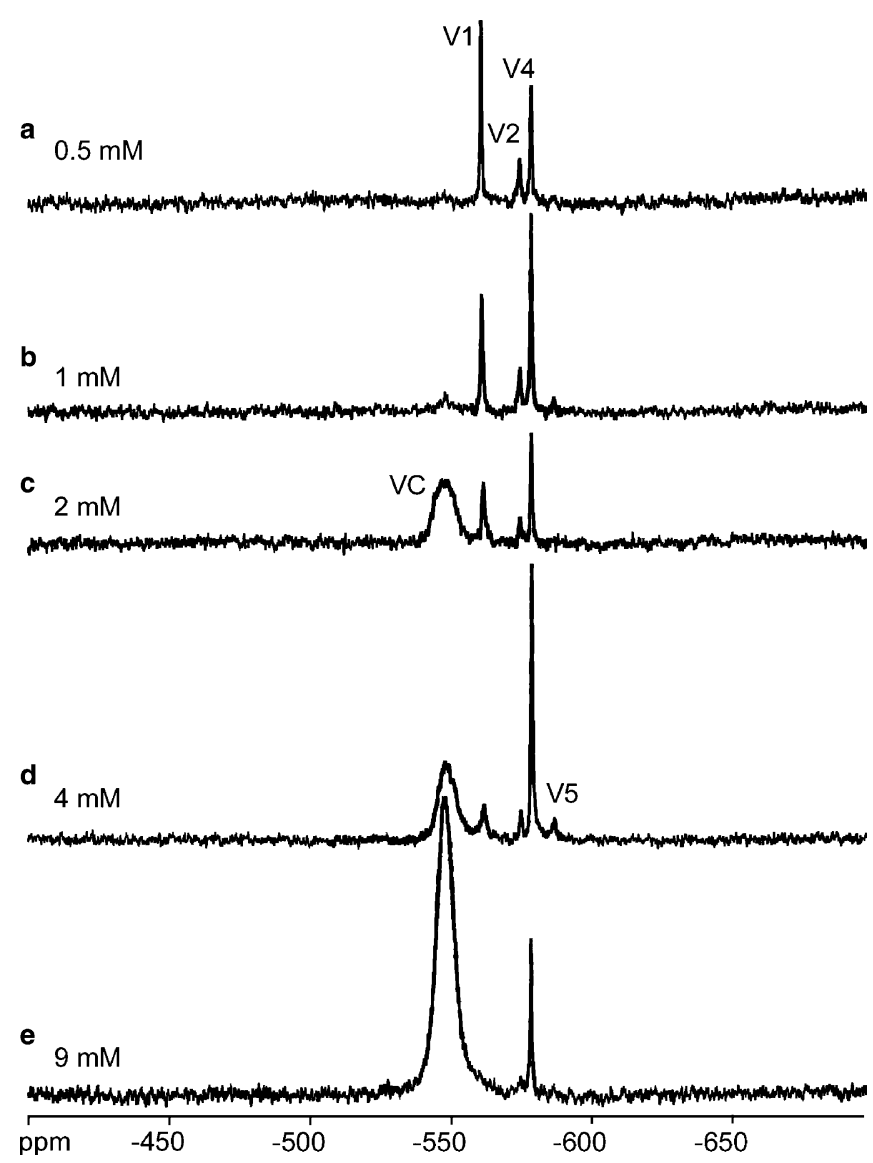

Fig. 2. $105.2 \mathrm{MHz}{ }^{51} \mathrm{~V}$ NMR spectra, at $22{ }^{\circ} \mathrm{C}$, of different concentrations, namely $0.5 \mathrm{mM}$ (a); $1 \mathrm{mM}$ (b); $2 \mathrm{mM}$ (c); $4 \mathrm{mM}$ (d) and $9 \mathrm{mM}$ (e) total vanadium, of a vanadium(V)-citrate (VC) complex in a medium containing $25 \mathrm{mM}$ Hepes, $\mathrm{pH} 7.0$, and $0.1 \mathrm{M} \mathrm{KCl}$. V1 and V2 NMR signals correspond, respectively, to monomeric $\left(\mathrm{H}_{2} \mathrm{VO}_{4}^{-}\right)$and dimeric $\left(\mathrm{HV}_{2} \mathrm{O}_{7}^{3-}\right.$ and $\left.\mathrm{H}_{2} \mathrm{~V}_{2} \mathrm{O}_{7}^{2-}\right)$ vanadate species irrespective of the protonation state, whereas $\mathrm{V} 4$ and $\mathrm{V} 5$ correspond to cyclic tetrameric $\left(\mathrm{V}_{4} \mathrm{O}_{12}^{4-}\right)$ and pentameric $\left(\mathrm{V}_{5} \mathrm{O}_{15}^{5-}\right)$ vanadate species.

(V1) at $-561 \mathrm{ppm}$, dimeric (V2) at $-574 \mathrm{ppm}$ and tetrameric (V4) at $-578 \mathrm{ppm}$ vanadate species were observed, whereas the VC NMR resonance at $-546 \mathrm{ppm}$ 
almost disappeared at concentrations as low as $1 \mathrm{mM}$ in total vanadium (Fig. 2).

Three NMR signals are observed for the peroxovana$\operatorname{dium}(\mathrm{V})$ :citrate $(\mathrm{PVC})$ complex dissolved in water $(\mathrm{pH}$ 4.4) or in the reaction medium ( $9 \mathrm{mM}$ total vanadium). The signals appear at $-542 \mathrm{ppm}$ (PVC1), $-551 \mathrm{ppm}$ (PVC2) and $-609 \mathrm{ppm}(\mathrm{PV})$, with the half line widths of these signals being about 200,150 and $100 \mathrm{~Hz}$, respectively (Fig. 3). The relative areas show a first signal twice as large as the second, probably reflecting conformers of the same complex. The NMR signal observed at $-609 \mathrm{ppm}$ (PV, Fig. 3) is due to an oxoperoxovanadium(V) species, indicating that the PVC complex dissociates as well. Furthermore, upon dissolution of the PVC complex in the reaction medium, at lower concentrations (from 4 to $0.5 \mathrm{mM}$ ), it is partially converted into vanadate oligomers (Fig. 4), a behaviour that was also observed above for VC complex. The two complexes as discrete chemical species possess their own chemical properties reflected in unique pattern of degradation. To this end, the PVC complex appears to be more stable toward ultimate vanadate oligomer degradation than the VC complex. That can be easily attested by ${ }^{51} \mathrm{~V}$ NMR, showing that the vanadate oligomers signals are solely and clearly observed for concentrations $\left[\mathrm{V}_{\text {total }}^{V}\right] \leqslant 1 \mathrm{mM}$ (Fig. 4). In fact, the species composition of the VC and PVC complex solutions varies with the total vanadium concentration (Fig. 5). At vanadium concentrations up to $2 \mathrm{mM}$, different species occur simultaneously for both the VC and PVC complexes, whereas at higher vanadium $(\mathrm{V})$ concentrations the $\mathrm{VC}$ and PVC complexes are favoured. Even for solutions $9 \mathrm{mM}$ in total vanadium, only about 4.2 and $3.6 \mathrm{mM}$ of VC and PVC complexes are present, respectively (Fig. 5). Therefore, it was difficult to obtain a solution containing exclusively a single vanadium(V) species, and even when that was achieved, other species appeared when the solution was diluted in the reaction medium. Consequently,

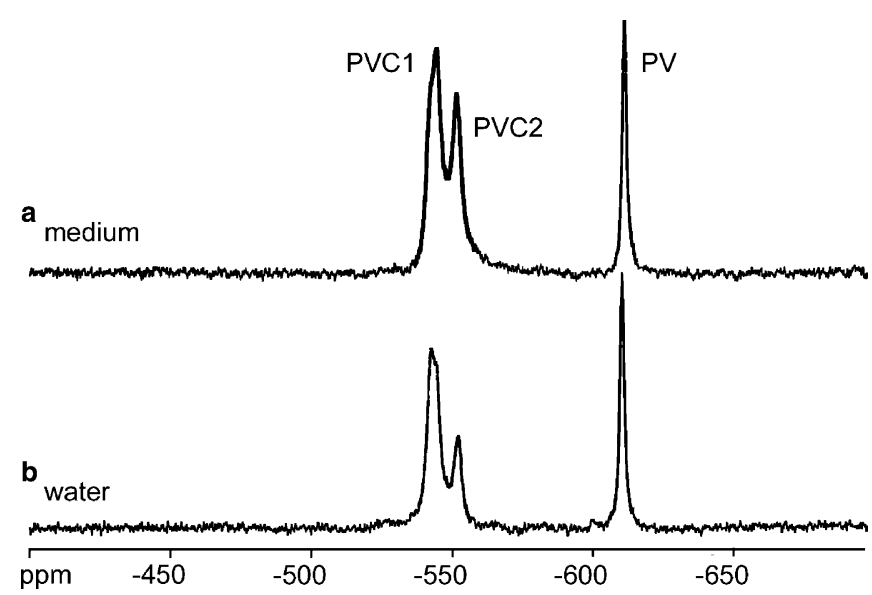

Fig. 3. $105.2 \mathrm{MHz}{ }^{51} \mathrm{~V}$ NMR spectra, at $22{ }^{\circ} \mathrm{C}$, of a $9 \mathrm{mM}$ peroxovana$\operatorname{dium}(\mathrm{V})$-citrate complex solution prepared in water (a) or in the reaction medium (b). PVC1 and PVC2 stands for peroxovanadium(V)-citrate species, while PV stands for oxoperoxovanadium(V) species.

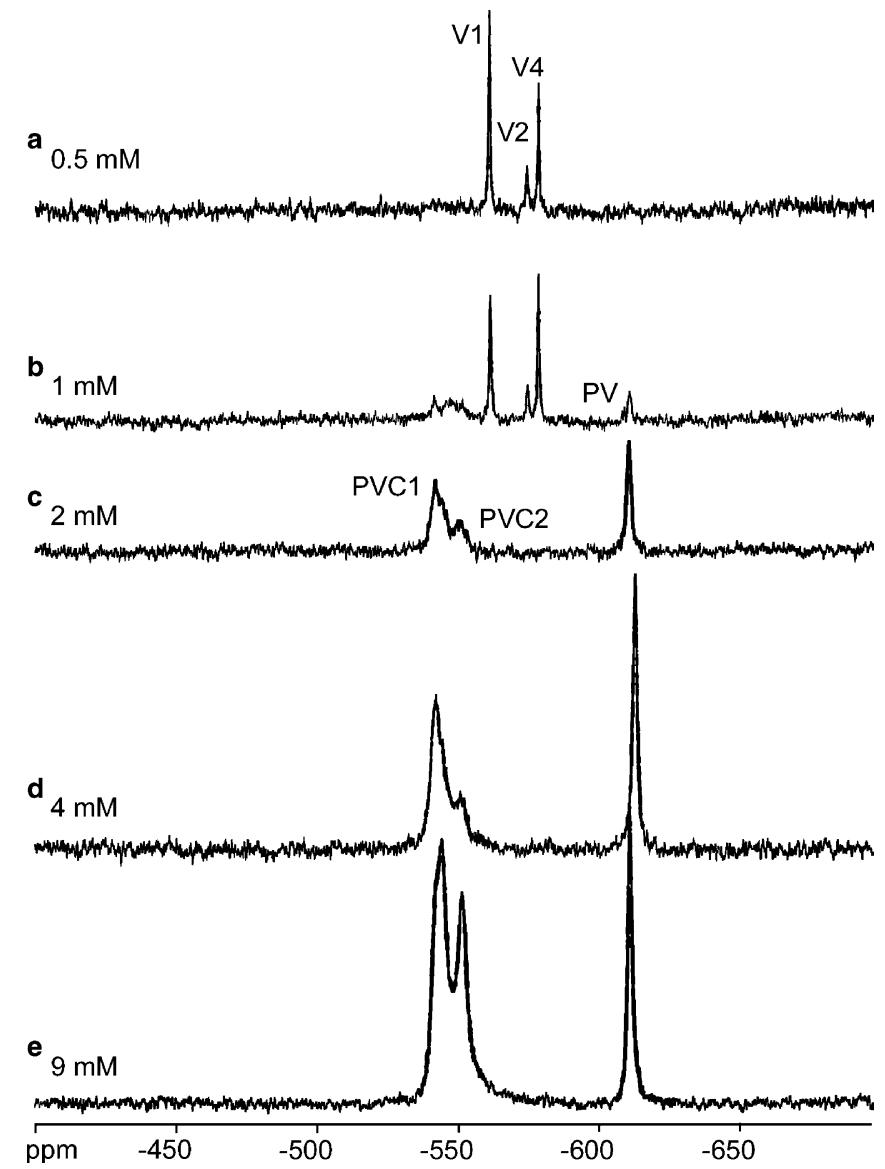

Fig. 4. $105.2 \mathrm{MHz}{ }^{51} \mathrm{~V}$ NMR spectra, at $22^{\circ} \mathrm{C}$, of different concentrations of a peroxovanadium $(\mathrm{V})$-citrate (PVC) complex in a medium containing $25 \mathrm{mM}$ Hepes, $\mathrm{pH}$ 7.0, and $0.1 \mathrm{M} \mathrm{KCl}: 0.5 \mathrm{mM}$ (a); $1 \mathrm{mM}$ (b); $2 \mathrm{mM}$ (c); $4 \mathrm{mM}$ (d) and $9 \mathrm{mM}$ (e) total vanadium. V1 and V2 NMR signals correspond, respectively, to monomeric $\left(\mathrm{H}_{2} \mathrm{VO}_{4}^{-}\right)$and dimeric $\left(\mathrm{HV}_{2} \mathrm{O}_{7}^{3-}\right.$ and $\mathrm{H}_{2} \mathrm{~V}_{2} \mathrm{O}_{7}^{2-}$ ) vanadate species irrespective of the protonation state, whereas $\mathrm{V} 4$ correspond to cyclic tetrameric $\left(\mathrm{V}_{4} \mathrm{O}_{12}^{4-}\right)$ vanadate species. $\mathrm{PVC} 1$ and PVC2 stands for peroxovanadium(V)-citrate species, while PV stands for oxoperoxovanadium(V) species.

in order to investigate the interactions and effects of the complexes with the SR calcium pump, higher concentrations were used.

\section{2. ${ }^{51} V$ NMR study on the interaction of the complexes with $S R$ calcium pump}

Upon addition of sarcoplasmic reticulum vesicles (SRV, $2.5 \mathrm{mg} / \mathrm{ml}$ of total protein) to the $\mathrm{VC}$ complex solution ( $2 \mathrm{mM}$ total vanadium) prepared in the reaction medium, the ${ }^{51} \mathrm{~V}$ NMR signal at $-548 \mathrm{ppm}$ broadens (from 506 to $657 \mathrm{~Hz}$ ) and its intensity decreases (Fig. 6(a)). This solution, however, contains vanadate oligomers, with the tetrameric vanadate signal resonance sustaining an enormous decrease in intensity upon SRV addition. In contrast, as it was observed by ${ }^{51} \mathrm{~V}$ NMR, the PVC complex solution ( $2 \mathrm{mM}$ total vanadium) prepared in the reaction medium does not contain vanadate oligomers and thus the interactions with the SR calcium pump can only be related to the 

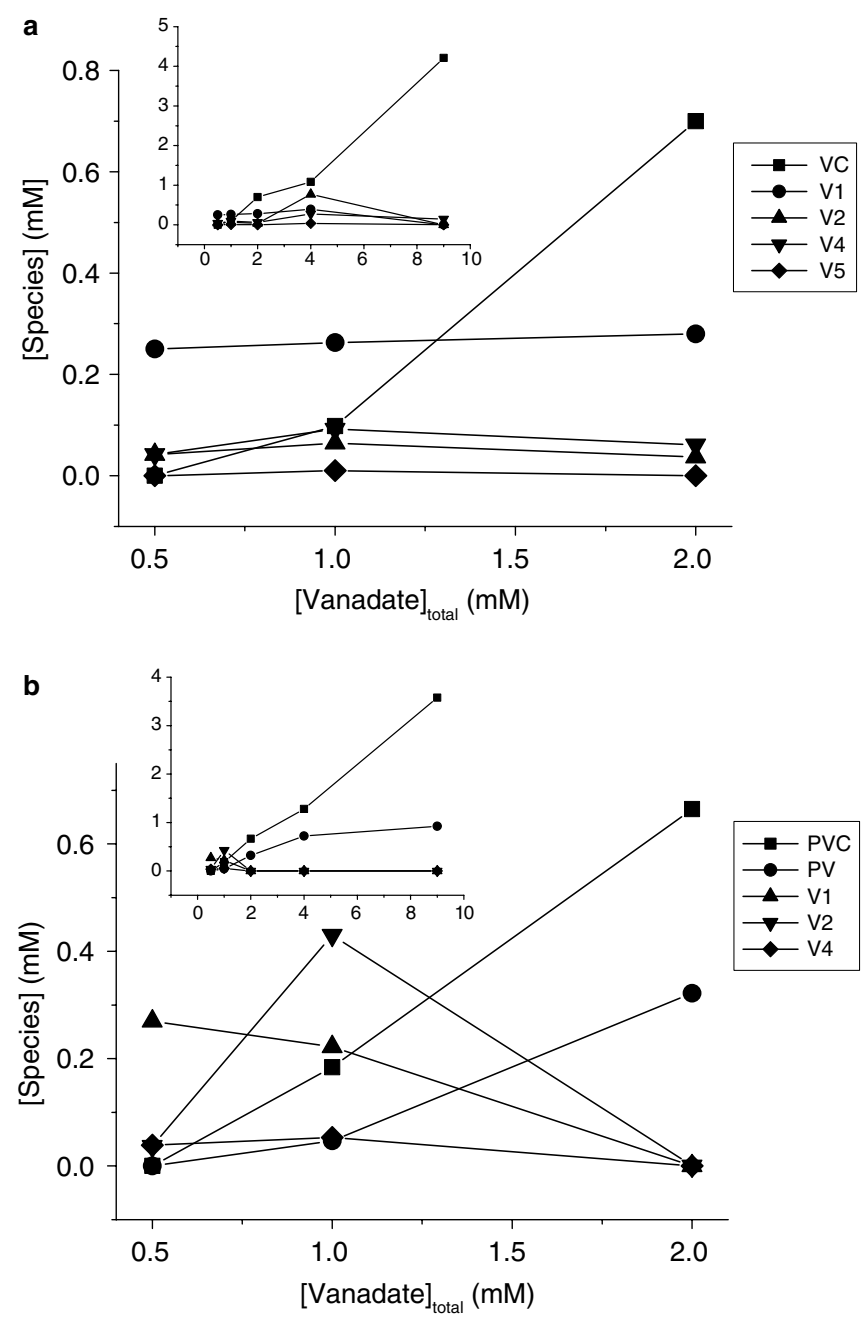

Fig. 5. Vanadium(V) species composition of vanadium(V)-citrate (a) and peroxovanadium(V)-citrate (b) solutions used in the assays. A series of ${ }^{51} \mathrm{~V}$ NMR spectra of vanadium(V)-citrate and peroxovanadium(V)citrate solutions were recorded at concentrations up to $9 \mathrm{mM}$, in a medium containing $25 \mathrm{mM}$ Hepes, $\mathrm{pH} 7.0,0.1 \mathrm{M} \mathrm{KCl}$, at $22^{\circ} \mathrm{C}$. The concentrations of each vanadium $(\mathrm{V})$ species were calculated from the fractions of the total integrated areas observed in the spectra.

peroxovanadium $(\mathrm{V})$ complex affinity for the protein. Both signals detected at -542 and $-609 \mathrm{ppm}$, ascribed to the PVC complex and to PV, broadened from 175 to $281 \mathrm{~Hz}$ and from 93 to $112 \mathrm{~Hz}$, respectively, and decreased in intensity in the presence of the calcium pump (Fig. 6(b)). Putting all together, the relative order of the half width line broadening for the NMR signals, which reflect the interaction of the complexes with protein, was $\mathrm{V} 4>\mathrm{PVC}>$ $\mathrm{VC}>\mathrm{PV}>\mathrm{V} 2=\mathrm{V} 1=1$, with no effects observed for the V1 and V2 signals. Moreover, upon phosphorylation by Pi or ATP following the methodology described elsewhere [12], the different forms E2 and E1 of the enzyme did not affect the NMR signals of the complexes observed following SRV addition (not shown).

Early ${ }^{51} \mathrm{~V}$ NMR studies on the binding of various ionic forms of vanadate to SRV have clearly shown that the NMR resonances for the free oligomeric species of vana-
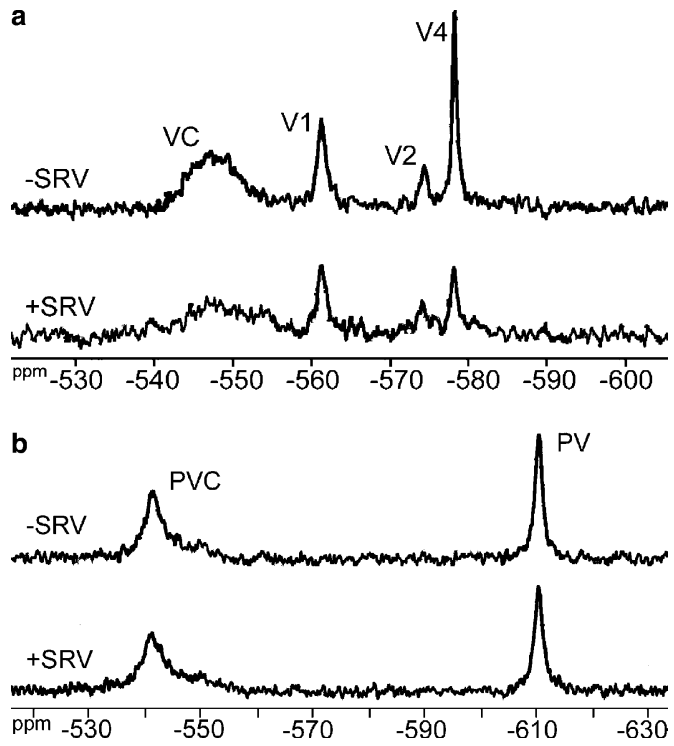

Fig. 6. $105.2 \mathrm{MHz}{ }^{51} \mathrm{~V}$ NMR spectra of $2 \mathrm{mM}$ vanadium(V)-citrate complex (a) or peroxovanadium(V)-citrate (b) in a medium containing $25 \mathrm{mM}$ Hepes, pH 7.0, $0.1 \mathrm{M} \mathrm{KCl}, 5 \mathrm{mM} \mathrm{MgCl}_{2}$, in the absence (-SRV) or in the presence $(+\mathrm{SRV})$ of sarcoplasmic reticulum vesicles $(2.5 \mathrm{mg} / \mathrm{ml}$ total protein).

date, present at $\mathrm{pH} 7.4$, decrease upon addition of the protein [21]. More recently, it was demonstrated that the changes in the NMR spectra are caused by alterations in the $\mathrm{Ca}^{2+}$-ATPase induced by ATP [12]. These authors described that the signals for tetrameric vanadate increase in intensity and become narrower, whereas the signal for monomeric vanadate become broader, suggesting that ATP increases the affinity of monomeric species for the enzyme but decreases the affinity for the tetrameric species. In studies with myosin, similar findings were reported for tetrameric and monomeric species following ATP addition [22].

Different SR ATPase conformational forms arisen from the presence of specific ligands can be ascribed to vana$\operatorname{dium}(\mathrm{V})$ affinities for the protein. Our data indicate that the affinity of both vanadium $(\mathrm{V})$ complexes is not apparently affected when the different forms E2 and E1 of the enzyme are induced. Moreover, the affinity for both forms of the ATPase does not change upon phosphorylation by $\mathrm{Pi}$ or ATP. It has been suggested that "monovanadate" species may bind to the ATPase in the vicinity of the aspartyl phosphate acceptor, resulting in the blockage of the active site by avoiding phosphoenzyme intermediate formation, whereas the decavanadate binding site to the enzyme has been reported to be very close to the ATP binding site $[13,15]$. In the present work, it is suggested that the vana$\operatorname{dium}(\mathrm{V})$ complexes may modulate the calcium pump through a different interaction than the one observed for vanadate oligomers. This indicates that the complexity of vanadium effects is not only due to the presence of different oligomers in solution, which were shown to promote different in vivo effects [23], but also to the influence of potential ligand binders of vanadium in biological systems. 
3.3. Inhibition of ATPase hydrolysis and $\mathrm{Ca}^{2+}$ accumulation by VC and PVC complexes

The inhibition promoted on the SR calcium pump ATP hydrolysis process was similar for both VC and PVC complex solutions, with a $50 \%$ inhibition at $0.5 \mathrm{mM}$ (Fig. 7). However, with respect to $\mathrm{Ca}^{2+}$ accumulation by the SR calcium pump, the PVC complex solution exerted a stronger inhibition on this process, with an $\mathrm{IC}_{50}$ value of $1.1 \mathrm{mM}$ (Fig. 7(b)), compared to a $2.0 \mathrm{mM} \mathrm{IC}_{50}$ value for the VC complex solution promoting the same effect (Fig. 7(a)). Under the same experimental conditions, it was observed that metavanadate does not affect $\mathrm{Ca}^{2+}$ accumulation by the calcium pump. However, as it can be observed in Fig. 7, $1 \mathrm{mM}$ solu-
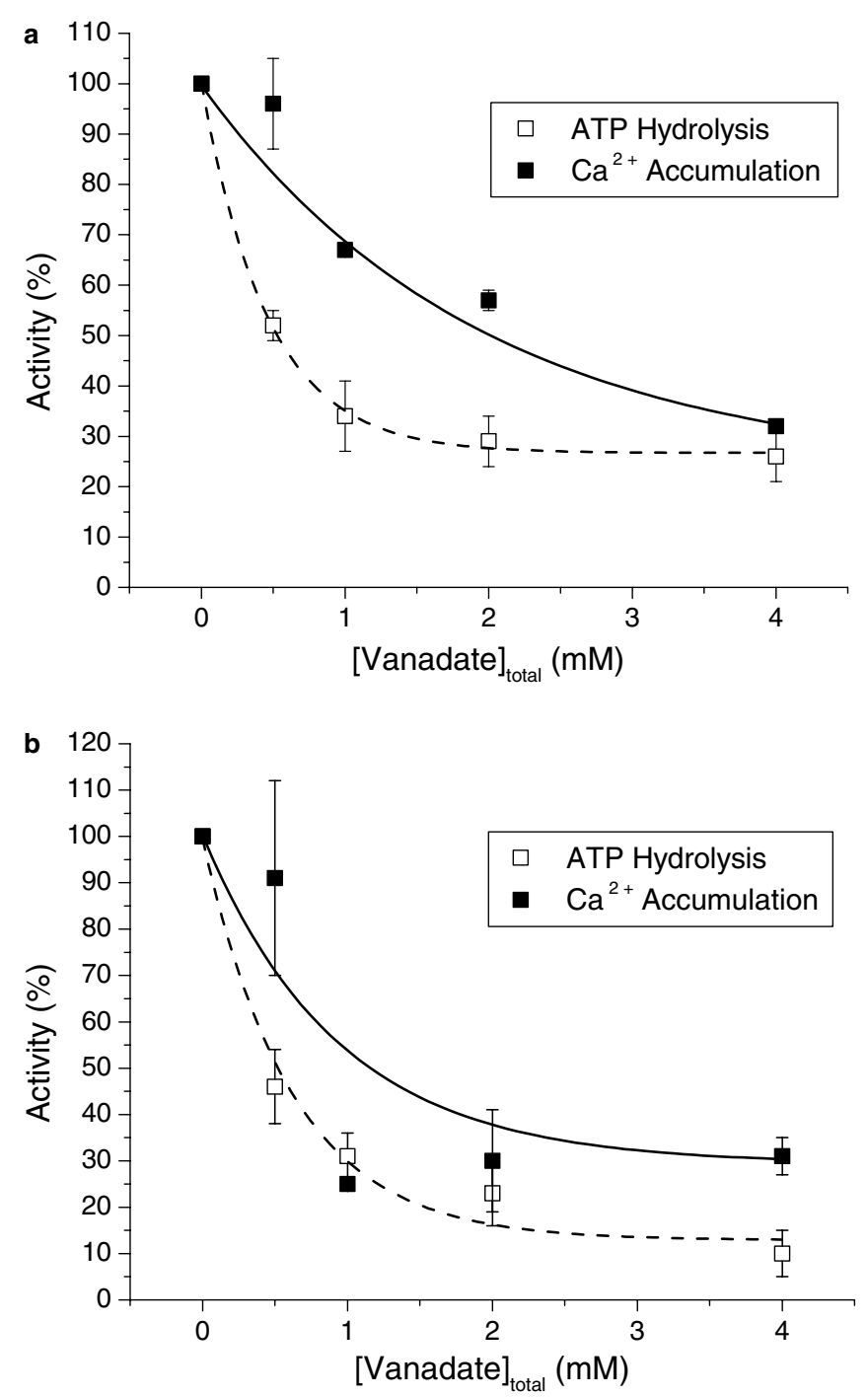

Fig. 7. Effects of the vanadium(V)-citrate complex (a) and peroxo vanadium(V)-citrate complex (b) solutions, on phosphate production during ATP splitting (dashed line, open squares) and $\mathrm{Ca}^{2+}$ accumulation (solid line, solid squares) by the SR calcium pump. The reactions were monitored at $25^{\circ} \mathrm{C}$, in an assay medium containing $0.1 \mathrm{M} \mathrm{KCl}, 5 \mathrm{mM}$ $\mathrm{MgCl}_{2}, 50 \mu \mathrm{M} \mathrm{CaCl}, 285 \mu \mathrm{g} / \mathrm{ml}$ protein or $100 \mu \mathrm{g} / \mathrm{ml}$ (according to Section 2) and $25 \mathrm{mM}$ Hepes, $\mathrm{pH}$ 7.0. The reactions were started upon addition of $500 \mu \mathrm{M} \mathrm{MgATP}$ and were monitored for $10 \mathrm{~min}$. The provided rates reflect the means of at least six independent experiments. tion of the PVC complex inhibits the $\mathrm{Ca}^{2+}$ accumulation by $75 \%$, whereas a solution of the VC complex of the same vanadium concentration inhibits the calcium pump activity by $33 \%$, meaning that the $\mathrm{IC}_{50}$ value obtained for the latter complex is eventually lower than the obtained through the function that fits the graph. Even so, if we considered the obtained $\mathrm{IC}_{50}$ values, the $\mathrm{Ca}^{2+} /$ ATP stoichiometry was affected differently by both complex solutions: the VC complex induced an increase in pump efficiency (thereby increasing $\mathrm{Ca}^{2+}$ /ATP ratio), whereas the PVC complex did not affect $\mathrm{Ca}^{2+} /$ ATP stoichiometry. For the former complex the effects may not be exclusively attributed to it, without define the influence of the PV species on the inhibition of ATPase hydrolysis and $\mathrm{Ca}^{2+}$ accumulation.

In order to evaluate the effect of citrate alone, a structural component of these vanadium $(\mathrm{V})$-citrate complex solutions, on the inhibition registered by $\mathrm{VC}$ and PVC complexes, the ATP hydrolysis and $\mathrm{Ca}^{2+}$ accumulation processes were measured in the presence of several citrate concentrations. It was observed that citrate induced an increase in sarcoplasmic reticulum $\mathrm{Ca}^{2+}$ accumulation, with no discernible effect on the hydrolytic activity (not shown). In fact, $\mathrm{Ca}^{2+}$ accumulation increased by $23 \%$ and $70 \%$ in the presence of 2 and $4 \mathrm{mM}$ citrate, respectively. This effect may explain the increase in $\mathrm{Ca}^{2+} /$ ATP ratio observed for the VC complex (Fig. 7(a)). In contrast, citrate did not affect the inhibition by the PVC complex, even though it was verified that the complex dissociates, giving rise to oligomers and also to oxoperoxovanadium $(\mathrm{V})$ and therefore inducing, to a lower extent than the VC complex, the appearance of citrate.

\section{Concluding remarks}

${ }^{51} \mathrm{~V}$ NMR spectroscopy was used to determine the composition of the VC and PVC complex solutions in the reaction medium and then to calculate the concentrations of the various species present in solution relative to the total vanadium concentration. In the concentration range used, it was observed that the vanadium $(\mathrm{V})$ complex solutions contain, besides vanadium $(\mathrm{V})$ complexes and oxoperoxovanadium(V) species, different amounts of mono (V1); di (V2); tetra (V4) and pentameric (V5) species (Fig. 6). NMR spectra of a $1 \mathrm{mM}$ VC complex solutions in the reaction medium indicated that the solutions contain $98 \mu \mathrm{M}$ of complex, $263 \mu \mathrm{M}$ monomeric (V1), $64 \mu \mathrm{M}$ dimeric (V2) and $92 \mu \mathrm{M}$ tetrameric (V4) species, whereas a $1 \mathrm{mM}$ PVC complex solutions contain $184 \mu \mathrm{M}$ of complex, $94 \mu \mathrm{M}$ oxoperoxovanadium $(\mathrm{V})$ species, $222 \mu \mathrm{M}$ monomeric (V1), $43 \mu \mathrm{M}$ dimeric (V2) and $53 \mu \mathrm{M}$ tetrameric (V4) species. It should be noted that a $1 \mathrm{mM}$ of metavanadate solution contains, under the same experimental conditions, about $460 \mu \mathrm{M}$ monomeric, $90 \mu \mathrm{M}$ dimeric and $80 \mu \mathrm{M}$ tetrameric vanadate species. The unique nature of the title complexes investigated and their emerging patterns of degradation in aqueous media dictate a commensurately unique biological activity exerted in the presence of the biological target (the 
SR system). These solutions, with equivalent vanadium(V) concentrations, inhibit $\mathrm{Ca}^{2+}$ accumulation to variable degrees, namely $75 \%, 33 \%$ and $2 \%$ for PVC, VC and metavanadate solutions, respectively. These results point out an interesting behaviour of the vanadate complexes. Specifically, based on total vanadium concentration of vanadium present in the ternary PVC and binary VC complex solutions of the same $1 \mathrm{mM}$ concentration, the PVC complex is more potent (2.3 times higher) than the VC complex. Thus, the peroxovanadate complex appears to be a more potent inhibitor of the calcium pump.

It is considered to be of primary importance to precisely characterize the vanadium species that could interact with an enzyme system prior to attempting to investigate any effects promoted by vanadium(V)-containing solutions. To that end, it was not possible to clearly define the effects promoted by each individual vanadium(V)-citrate complex. Concomitantly, due to the complexity of the system, which contains several vanadium $(\mathrm{V})$ species interacting with multiple sites on the $\mathrm{Ca}^{2+}$-ATPase, that can adopt several conformations, it was not possible to completely define the effects of the vanadium $(\mathrm{V})$ :citrate species on sarcoplasmic reticulum $\mathrm{Ca}^{2+}$-ATPase activity. It was clear, however, that enzyme activity inhibition increases in the presence of the title complexes, suggesting an interaction of vanadium with the sarcoplasmic reticulum $\mathrm{Ca}^{2+}$-ATPase different from that exhibited by other vanadate oligomers.

\section{Acknowledgements}

This work was supported by the POCTI program funded through FEDER, research project POCTI/38191/ QUI/2001. Rui O. Duarte thanks to PostDoc Grant SFRH/BPD/8912/2002 and T. Tiago thanks to Ph.D. Grant SFRH/BD/2924/2000, both from the Portuguese Ministry of Education, through "Fundação para a Ciência e Tecnologia".

\section{References}

[1] L. Josephson, L.C. Cantley Jr., Biochemistry 16 (1977) 4572-4578.

[2] L.C. Cantley Jr., L. Josephson, R. Warner, M. Yanagisawa, C. Lechene, G. Guidotti, J. Biol. Chem. 252 (1977) 7421-7423.

[3] L.A. Beaugé, I.M. Glynn, Nature 272 (1978) 551-552.

[4] Y. Shechter, Diabetes 39 (1990) 1-5.

[5] D.C. Crans, J.J. Smee, E. Gaidamauskas, L. Yang, Chem. Rev. 104 (2004) 849-902.

[6] A.K. Srivastava, M.Z. Mehdi, Diabet. Med. 22 (2005) 2-13.

[7] M. Tsaramyrsi, D. Kavousanaki, C. Raptopoulou, A. Terzis, A. Salifoglou, Inorg. Chim. Acta 320 (2001) 47-59.

[8] M. Tsaramyrsi, M. Kaliva, A. Salifoglou, C. Raptopoulou, A. Terzis, V. Tangoulis, J. Giapintzakis, Inorg. Chem. 40 (2001) 5772-5779.

[9] A. Gorzsás, K. Getty, I. Andersson, L. Pettersson, Dalton Trans. (2004) 2873-2882.

[10] U. Pick, J. Biol. Chem. 257 (1982) 6111-6119.

[11] L. De Meis, A.L. Vianna, Annu. Rev. Biochem. 48 (1979) 275 292.

[12] M. Aureliano, V.M.C. Madeira, Biochim. Biophys. Acta 1221 (1994) 259-271.

[13] M. Aureliano, V.M.C. Madeira, in: J.O. Nriagu (Ed.), Vanadium in the Environment, Part 1: Chemistry and Biochemistry, Wiley, New York, 1998, pp. 333-357.

[14] K.R. Bidasee, Y. Zhang, C.H. Shao, M. Wang, K.P. Patel, U.D. Dincer, H.R. Besch Jr., Diabetes 53 (2004) 463-473.

[15] S. Hua, G. Inesi, C. Toyoshima, J. Biol. Chem. 275 (2000) 3054630550 .

[16] Y. Gutiérrez-Martin, F.J. Martín-Romero, F.A. Iñesta-Vaquera, C. Gutiérrz-Merino, F. Henao, Eur. J. Biochem. 271 (2004) 26472657.

[17] M. Kaliva, C.P. Raptopoulou, A. Terzis, A. Salifoglou, J. Inorg. Biochem. 93 (2003) 161-173.

[18] M. Kaliva, C.P. Raptopoulou, A. Terzis, A. Salifoglou, Inorg. Chem. 43 (2004) 2895-2905.

[19] A.G. Gornall, C.J. Bardawill, M.M. Davis, J. Biol. Chem. 177 (1949) $751-766$.

[20] C.H. Fiske, Y. Subbarow, J. Biol. Chem. 66 (1925) 375-400.

[21] P. Csermely, A. Martonosi, G.C. Levy, A.J. Ejchart, Biochem. J. 230 (1985) 807-815.

[22] T. Tiago, M. Aureliano, R.O. Duarte, J.J. Moura, Inorg. Chim. Acta 339 (2002) 312-321.

[23] R.M.C. Gândara, S.S. Soares, H. Martins, C. Gutiérrez-Merino, M. Aureliano, J. Inorg. Biochem. 99 (2005) 1238-1244. 